\title{
Development of Web-Based Spatial Information System Tourism Industry Event Distribution (Case Study)
}

\author{
Muhammad Syaifullah Mahfudz ${ }^{1}$, Zainul Arham², Eva Khudzaeva ${ }^{3}$
}

\begin{abstract}
In recent years, the number and scope of events in the Asia and Middle East/North Africa region has increased significantly. Events are one of the things that attracts the attention of foreign tourists to come to visit a country as a tourist destination. Refers to Minister of Tourism Regulation Number 2 Year 2017 on Guidelines for Venues for Meetings, Incentive Trips, Conventions and Exhibitions, explains that criteria and indicators are needed to increase the competitiveness of venues for meetings, incentive trips, conventions and exhibitions at the regional and global levels. This is done to increase the number of visits, length of stay, and expenditures for domestic and foreign tourists. Therefore, visual indicators or data are needed that can present the location of the event and a list of events in DKI Jakarta. From these problems, this study aims to produce a web-based spatial information system for the distribution of tourism industry events to map event locations in DKI Jakarta. The methodology used in collecting this data is the method of observation, interviews, and literature studies. While the system development methodology uses PHP and MySQL with the Rapid Application Development (RAD) approach and uses the Unified Modeling Language (UML) which is a tool for system description and design, as well as the Google Maps API for digital maps. The results of this study are in the form of a spatial information system that can display a map of the distribution of event locations in DKI Jakarta based on event data and event categories at the DKI Jakarta Tourism and Creative Economy Department..
\end{abstract}

Keywords - Spatial Information Systems, Tourism Industry Events, Unified Modeling Language, Rapid Application Development

\section{INTRODUCTION}

A ccording to [1] event is a special ritual, performance, appearance or celebration that must be carried out and planned which is usually made to mark special occasions. The event has the aim of achieving a social, cultural, and so on. While the definition of tourism events according to [2], the systematic planning, development and marketing of planned events as tourist attractions and for their benefit in marketing the place, shaping its image and development. Tourism events

Received: 3 November 2020 ; Revised: 7 Januari 2021 ; Accepted: 7 Januari 2021

${ }^{1}$ M.S. Mahfuz, PT. Sapua Edukasi, Indonesia (e-mail: muhammad.syaifullah15@mhs.uinjkt.ac.id)

http://journal.uinjkt.ac.id/index.php/aism are an important segment of the tourism industry and have the potential to provide substantial economic, social, cultural and environmental benefits to the destination [3].

In recent years, the number and scope of events in the Asia and Middle East/North Africa region has increased significantly. Events are one of the things that attracts the attention of foreign tourists to come to visit a country as a tourist destination. Festivals and events are considered capable of extending tourist visit times, increasing market awareness, encouraging investment, generating income, and improving the local economy. Major events also provide a spectacle that expresses personality and elevates a city's status [4].

According to the website Sectoral Statistics Portal of DKI Jakarta Province [5], the tourism industry in DKI Jakarta is one of the sectors that has contributed significantly to Regional Original Income (PAD) in recent years. Therefore, the DKI Jakarta Provincial Government through the Tourism and Culture Office (now the Tourism and Creative Economy Office) continues to make efforts to maximize the potential of tourist destinations.

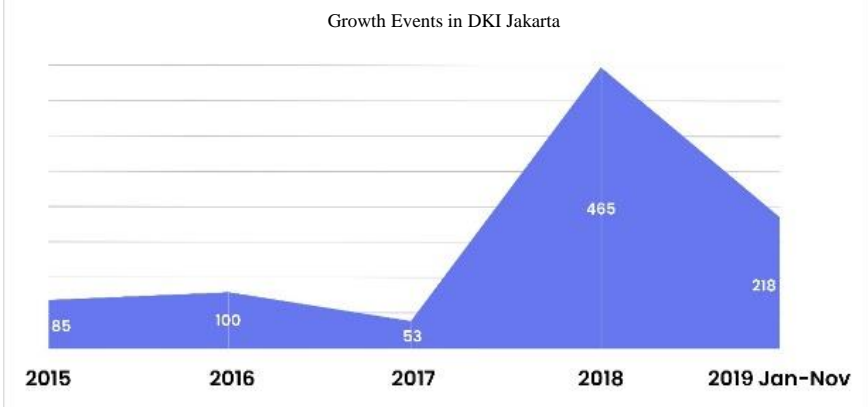

Fig. 1 Statistic of Number of Events in DKI Jakarta

Fig. 1 shows the data from the website [5], the number of events in DKI Jakarta has increased significantly in 2018. Recorded in the graphical data were 465 tourism and cultural

${ }^{2}$ A. Zainul, Department of Information System UIN Syarif Hidayatullah Jakarta, Indonesia (e-mail: zainul.arham@uinjkt.ac.id)

${ }^{3}$ E. Khudzaeva, Department of Information System UIN Syarif Hidayatullah Jakarta, Indonesia (e-mail: eva.khudzaeva@uinjkt.ac.id) 
events held in DKI Jakarta. In the website [6], the Jakarta Tourism and Culture Office (now the Tourism and Creative Economy Office) of DKI Jakarta divides event categories into 20 categories, namely Music, Film, Exhibition, Festival, Culture, Education, Workshop, Nightlife, Fashion, Traditional Art, Shopping, Culinary, Family, Art, Talk Show, Sport, Attractions, Technology, About Jakarta, Indonesia.

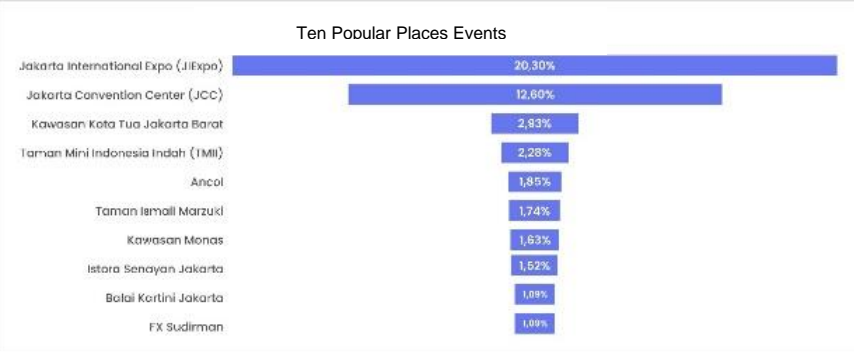

Fig. 2 The Popular Events Location

Fig. 2 shows data from 2015 to 2019, the majority of tourism and cultural events held in Jakarta were held at the Jakarta International Expo (JIExpo) and the Jakarta Convention Center (JCC). Apart from these two places, other popular places for holding tourism and cultural events are Kota Tua, Taman Mini Indonesia Indah (TMII), Ancol, Taman Ismail Marzuki, Monas, Istora Senayan, Balai Kartini and Sudirman.

According to [7], Guidelines for Venues for Meetings, Incentive Trips, Conventions and Exhibitions explain that criteria and indicators are needed to increase the competitiveness of venues for meetings, incentive trips, conventions and exhibitions at regional and global levels. This is done to increase the number of visits, length of stay, and expenditures for domestic and foreign tourists. Therefore, visual indicators or data are needed that can present the location of the event and a list of events in DKI Jakarta. The visual data in question is spatial data, according to [8], spatial data is information to describe existing facts, especially regarding the condition of an area or an area.

According to [9] concerning Tourism and several regulations in DKI Jakarta, including the regulations contained in [10] concerning the Implementation of Tourism Business which explains that every event organizer who wishes to register the event is required to have a TDUP (Tourism Business Registration Certificate) business license. If you already have the business license, event organizers can register the event at the DKI Jakarta Tourism and Creative Economy Office.

Meanwhile, the event registration process at the DKI Jakarta Tourism and Creative Economy Agency also has several regulations. Based on interviews with sources from the Data and Information Section Staff of the DKI Jakarta Province Tourism and Creative Economy Office, Mr. Bowo Pranoto, that registration for events in the DKI Jakarta area requires a letter permit from the Tourism and Creative Economy Office, Culture
Service, Regional Cooperation Bureau, Dinas Transportation, Police, Economic Bureau. If the event organizer already has a permit, the event organizer is allowed to publish the event via the website or contact via Instagram and email which will then be verified first by the curator. The resource person said that the problem that exists in the running system is that the event organizer is still unable to manage the event through the website and also users other than event organizers can register the event on the website. The resource person also said on the website of the DKI Jakarta Province Tourism and Creative Economy Office there was also no information on spatial data for the event distribution map in DKI Jakarta. Apart from this, the resource person wants to provide a discussion area for users to discuss events, share experiences, and see travel guides in participating in the event which can later be managed by the event organizer. This feature is expected to improve the tourism and economy sector in DKI Jakarta, given the many events and visitors who come from outside DKI Jakarta.

Based on the background explanation, the researcher is interested in conducting research in developing an information system that can display the distribution of event locations in DKI. This research will raise the title "Development of a WebBased Spatial Information System for the Distribution of Tourism Industry Events (Case Study: Dki Jakarta)".

\section{LITERATURE REVIEW}

According to [11], information system is something that includes a number of components (humans, computers, information technology, and work procedures), there is a process of processing data into information to achieve a goal or goal.

Geographical information system (GIS) is a computerbased system or technology that aims to collect, store, process and analyze, and present data and information from an object related to the location of the location on the earth's surface [12].

According to [8], spatial data is reliable information to describe existing facts, especially regarding the condition of an area or an area as a starting point for sustainable development.

According to [13] GIS has a function to improve the ability to analyze spatial information that is useful for planning and decision making. GIS can provide information that plays a role in making decisions for the purposes of analysis and application of spatial databases. GIS users can see the earth phenomenon with a better perspective. GIS also has the ability to accommodate storage, processing and display of digital spatial data and even integrate various data, ranging from satellite imagery, aerial photographs, maps and even statistical data.

\section{RESEARCH METHOD}

In this research, there are several ways to collect data. There are several ways to collect this data as follows:

http://journal.uinjkt.ac.id/index.php/aism 
A. Method of collecting data

1) Observation

In this case the researcher immediately sees or makes observations to the parts that have something to do with the object of research. Researchers observed the procedures and registration procedures for events at the DKI Jakarta Provincial Tourism and Creative Economy Office.

2) Interview

This activity is carried out by conducting questions and answers related to events in DKI Jakarta as well as procedures and registration procedures for events at the DKI Jakarta Provincial Tourism and Creative Economy Office. This interview was conducted with a resource person, Mr. Bowo Pranoto, as the staff of the data and information section in the field of destination and development.

3) Study of literature

A literature study was conducted by researchers to obtain data as reference material for the development of this spatial information system.

B. Systems Development Method

The development method used in this study is the RAD (Rapid Application Development) method. The RAD method is an object-oriented method.There are several stages in the RAD method used in this study, namely as follows: [14]

1) Requirements Planning Stage

- Data collection and information requirements

- Analyze running systems

- Identify problems with the system running

- Analyze the proposal system

2) Design Stage (Workshop Design)

- Process, database and interface design

3) Implementation Stage (Implementation)

- Programming

- System testing.

\section{RESULT}

\section{A. Running System}

Fig. 3 shows the rich picture of the current system implemented by the DKI Jakarta Provincial Tourism and Creative Economy Office for event registration.

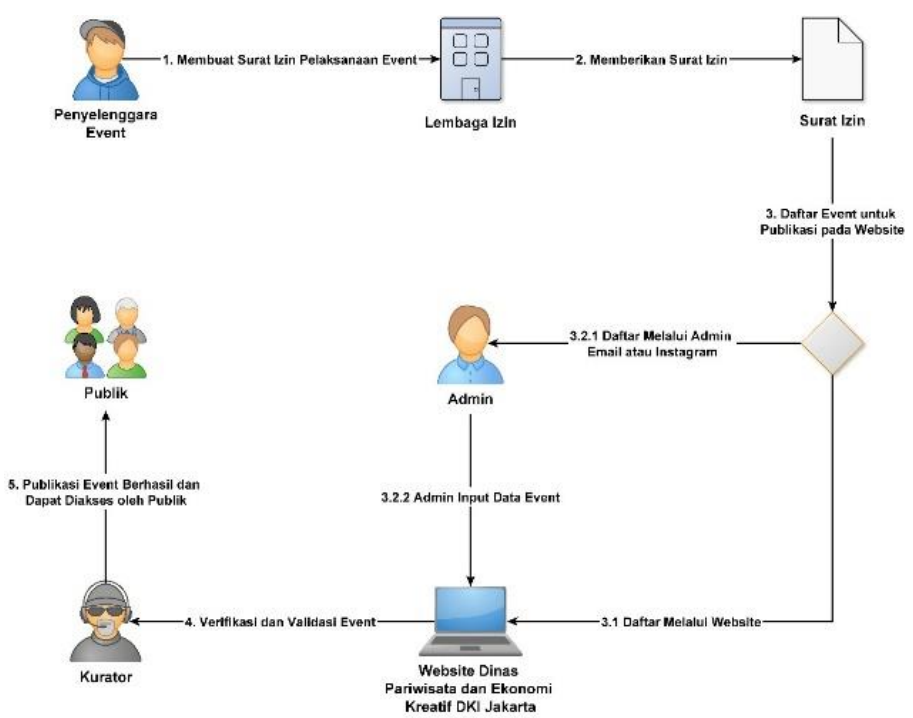

Fig. 3 Rich Picture of Current System in DKI Jakarta

The flow of the system can be described in the following points:

1) Event organizers who wish to register the event come to the Licensing Agency to obtain a permit for the event. The licensing agencies are the Tourism and Creative Economy Office, Culture Service, Regional Cooperation Bureau, Transportation Service, Police, Economic Bureau.

2) The Licensing Agency provides a letter to the event organizer.

3) Event organizers can register the event for publication via email, Instagram, or the website of the DKI Jakarta Province Tourism and Creative Economy Office.

a. If you register through the website, the event organizer must register an account first and fill out the form for event registration.

b. If you register via email or Instagram, the event organizer must write down the details of the event and attach an event permit letter to the Admin

c. Admin will verify the event and enter the event data into the website.

4) Event data that has been entered on the website will then be verified and validated by the Curator.

5) Event which has been verified and validated by the Curator will be published and can be accessed by the public.

In the results of the system analysis, the registration and publication flow of the DKI Jakarta Provincial Tourism and Creative Economy Office shows several problems that can be identified, namely:

1) The process of publishing the event is still not structured because there are event organizers who publish the event via the website or email or Instagram.

2) After the event is published, the event organizer cannot manage the event on the website. If the event organizer

http://journal.uinjkt.ac.id/index.php/aism 
wants to change the event information, they must contact the admin.

3) Registration for the event organizer's account on the website is not verified first.

4) All users other than the event organizer can register the event on the website.

5) Lack of complete information about event details when registering the event via email or Instagram.

6) There is no discussion space for users to discuss events, share experiences, and view travel guides in participating in the event.

7) There is no information regarding the distribution map showing the location of the event in DKI Jakarta.

B. Proposed System

The following Fig 4. is a proposed system, proposed by the researcher which is equipped with a description of the stages.

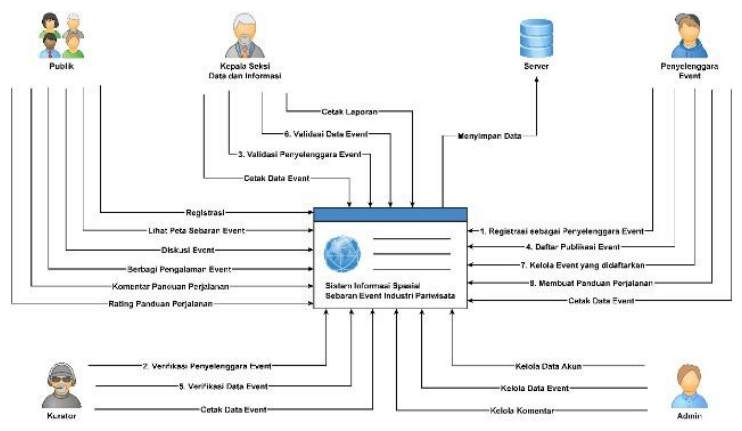

Fig 4. proposed system

The following is a description of the image of the proposed system, namely:

1) The event organizer registers an account as the event organizer by attaching the required documents.

2) Curator verifies the event organizer's account by checking the event organizer's documents.

3) After the account is verified, then the account will be validated by the Head of the Data and Information Section.

4) Event organizer accounts that have been verified and validated can register the event for publication by filling in the required data and attaching an event permit letter.

5) The curator will verify the event data whether the data entered is correct and complete.

6) Furthermore, event data will be validated by the Head of the Data and Information Section.

7) Event data that has been verified and validated can be managed by the event organizer.

8) Event organizers can also make travel guides to facilitate public access to visit published events.

After knowing the description of the proposed system, here are the benefits that will be obtained from the proposed system, namely:

1) Make it easier for admins to collect event data because the event publication process becomes more structured, which requires event organizers to complete event data through the system.

2) Make it easier for event organizers to manage events.

3) Make it easier for the curator to verify the event, because only the event organizer can publish the event.

4) Provides a discussion area for users to discuss events, share experiences, and view travel guides in following events.

5) Provides event distribution map information that displays the location of the event in DKI Jakarta.

The following is a use case diagram of the spatial information system distribution of tourism industry events.

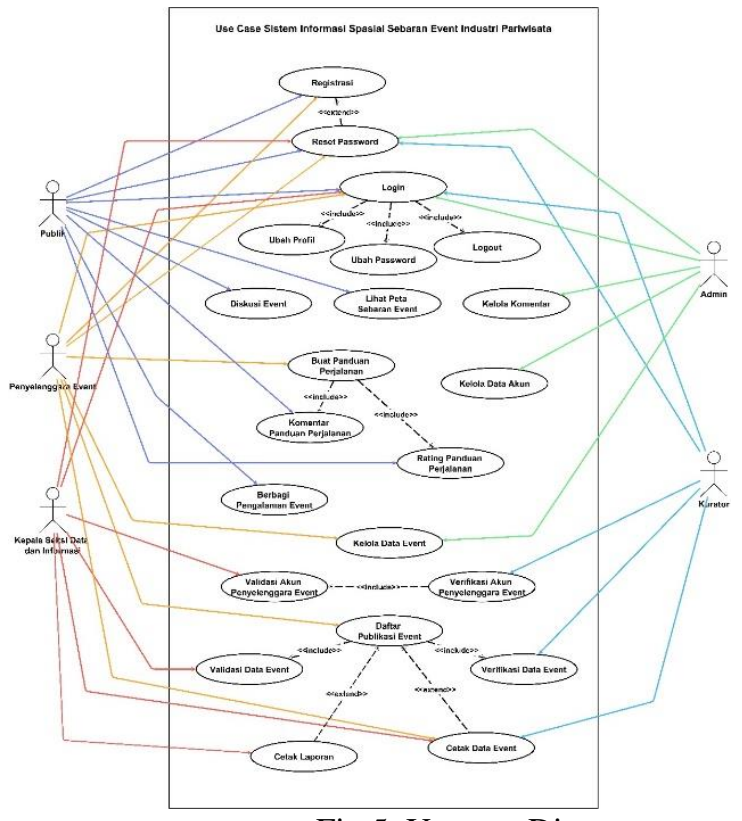

Fig 5. Usecase Diagram

From the figure 5. it explains that the use case diagram has 22 activities and 5 actors, namely the Admin, Event Organizer, Curator, Head of the Data and Information Section, and the Public.

\section{CONCLUSION}

Based on the problems and descriptions of the discussion in the previous chapter, the researcher can draw the following conclusions:

A. Produce a spatial information system for the distribution of tourism industry events that can display the location of the event and display the route from the user's location to the event location.

B. Generate information about the event category or classification on the event display.

C. Provide a different registration place between the public and the event organizer.

D. There is a system that can manage event data for event organizers, create event travel guides, and print event data.

http://journal.uinjkt.ac.id/index.php/aism 
E. Presenting an event discussion feature that makes it easier for users to discuss and share experiences that can provide user opinions or suggestions when visiting events.

Based on the previous analysis and conclusions, the suggestions for future research to be better include the following:

A. There are additional help on how to use the system such as a help menu provided for lay users.

$B$. Developing applications that can be integrated into the mobile platform.

Developing an event ticket purchase application that can be integrated with a payment gateway system to make it easier for users to buy event tickets

\section{REFERENCES}

[1] J. Allen, I. McDonnell, W. O'Toole, and R. Harris, Festival and Special Event Management. Wiley, 2002. https://books.google.co.id/books?id=XW-BQgAACAAJ

[2] F. Higgins, "Event Tourism and Event Imposition: A Critical Case Study From Kangaroo Island," South Australia. Journal of Tourism Management, vol. 64, pp. 73-86, 2017.
[3] J. Buultjens and G. Cairncross, "Event Tourism in Remote Areas: an Examination of the Birdsville Races," Journal of Place Management and Development, vol. 8, pp. 69-84, 2015.

[4] K. Weber and J. Ali-Knight, "Events and festivals in Asia and the Middle East/North Africa (MENA) region," International Journal of Event and Festival Management, vol. 3(1), pp. 4-8, 2012. doi:10.1108/17582951211210898

[5] Sectoral Statistics Portal of DKI Jakarta Province. (2019). Jakarta Tourism and Culture Event 2015-2019. http://statistik.jakarta.go.id/event-p Pariwisata-dan-kebultur-dki-jakarta-tahun-2015-2019/

[6] Jakarta Open Data. (2019). Data for the Jakarta Monthly Event Category in 2019. https://data.jakarta.go.id/dataset/data-kategory-event-jakarta

[7] Regulation of the Minister of Tourism Number 2. (2017). Guidelines for Venues for Meetings, Incentive Trips, Conventions and Exhibitions.

[8] B. Riadi, A. Syafi'i, and H.M. Widodo, Spatial Information System Development: A Case Study in Pidiejaya District, Aceh Province. Globe, 2011.

[9] Undang-Undang Number 10. (2009). Tourism.

[10] Regulation of the Governor of DKI Jakarta Number 18. (2018). Implementation of Tourism Business.

[11] A. Kadir, Introduction to Information Systems, Revised Edition. Yogyakarta: Penerbit Andi, 2014.

[12] E. Irwansyah, Geographical Information Systems: Basic Principles and Application Development. Digibooks, 2013.

[13] E. Prahasta, Geographical Information Systems Basic Concepts (Geodesy and Geodynamics Perspective). Informatics, 2014.

[14] K. E. Kendall and J.E. Kendall, System Analysis and Design. PT Index, 2010.

\footnotetext{
http://journal.uinjkt.ac.id/index.php/aism
} 
$\longrightarrow$ 